\title{
Decreased expression of Yes-associated protein is associated with outcome in the luminal $A$ breast cancer subgroup and with an impaired tamoxifen response
}

Sophie Lehn ${ }^{1 *}$, Nicholas P Tobin ${ }^{2}$, Andrew H Sims ${ }^{3}$, Olle Stål ${ }^{4}$, Karin Jirström ${ }^{5}$, Håkan Axelson ${ }^{6}$ and Göran Landberg ${ }^{7,8^{*}}$

\begin{abstract}
Background: Yes-associated protein (YAP1) is frequently reported to function as an oncogene in many types of cancer, but in breast cancer results remain controversial. We set out to clarify the role of YAP1 in breast cancer by examining gene and protein expression in subgroups of patient material and by downregulating YAP1 in vitro and studying its role in response to the widely used anti-estrogen tamoxifen.

Methods: YAP1 protein intensity was scored as absent, weak, intermediate or strong in two primary breast cancer cohorts ( $n=144$ and $n=564)$ and mRNA expression of YAP1 was evaluated in a gene expression dataset $(n=1107)$. Recurrence-free survival was analysed using the log-rank test and Cox multivariate analysis was used to test for independence. WST-1 assay was employed to measure cell viability and a luciferase ERE (estrogen responsive element) construct was used to study the effect of tamoxifen, following downregulation of YAP1 using siRNAs.

Results: In the ER+ (Estrogen Receptor a positive) subgroup of the randomised cohort, YAP1 expression was inversely correlated to histological grade and proliferation ( $p=0.001$ and $p=0.016$, respectively) whereas in the ER- (Estrogen Receptor a negative) subgroup YAP1 expression correlated positively to proliferation ( $p=0.005)$. Notably, low YAP1 mRNA was independently associated with decreased recurrence-free survival in the gene expression dataset, specifically for the luminal A subgroup ( $<0.001$ ) which includes low proliferating tumours of lower grade, usually associated with a good prognosis. This subgroup specificity led us to hypothesize that YAP1 may be important for response to endocrine therapies, such as tamoxifen, extensively used for luminal A breast cancers. In a tamoxifen randomised patient material, absent YAP1 protein expression was associated with impaired tamoxifen response which was significant upon interaction analysis $(p=0.042)$. YAP1 downregulation resulted in increased progesterone receptor (PgR) expression and a delayed and weaker tamoxifen in support of the clinical data.
\end{abstract}

Conclusions: Decreased YAP1 expression is an independent prognostic factor for recurrence in the less aggressive luminal A breast cancer subgroup, likely due to the decreased tamoxifen sensitivity conferred by YAP1 downregulation.

Keywords: Yes-associated protein, Breast cancer, Estrogen receptor, Luminal A, 11q deletion, Tamoxifen response, Independent prognostic factor

\footnotetext{
*Correspondence: sophie.lehn@med.lu.se; goran.landberg@gu.se

${ }^{1}$ Center for Molecular Pathology, Department of Laboratory Medicine, Lund

University, Skåne University Hospital, 20502 Malmö, Sweden

7Sahlgrenska Cancer Center, University of Gothenburg, 40530 Gothenburg,

Sweden

Full list of author information is available at the end of the article
}

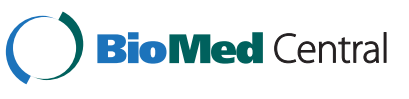

(c) 2014 Lehn et al.; licensee BioMed Central Ltd. This is an Open Access article distributed under the terms of the Creative Commons Attribution License (http://creativecommons.org/licenses/by/2.0), which permits unrestricted use, distribution, and reproduction in any medium, provided the original work is properly credited. The Creative Commons Public Domain Dedication waiver (http://creativecommons.org/publicdomain/zero/1.0/) applies to the data made available in this article, unless otherwise stated. 


\section{Background}

The Yes-associated protein (YAP1) was discovered in 1994 as a binding partner of the SH3 domain of the Yes proto-oncogene product [1]. Since then, a vast number of publications describing the structure and function of this transcriptional co-regulator have been published (reviewed in [2]). The YAP1 protein contains several binding motifs which allow for protein-protein interactions; for example the WW domain (present in either single or dual form due to splicing events [3]) which can bind and regulate proteins by interaction with a proline rich $\mathrm{PPxY}$ motif. YAP1 also contains a TEAD binding domain necessary for activation of the TEAD transcription factors, which upon aberrant activation leads to increased cell growth and proliferation, ultimately resulting in tissue overgrowth [4-7]. In addition, the activation of TEAD by YAP1 is reported to result in oncogenic transformation of several cell types $[8,9]$. YAP1 has been reported to bind and modulate the transcriptional activities of several proteins such as Runx2, TEAD, p73, ErbB4, Smad7 and Smad1 [7,10-15].

To date, there are several reports on the function of YAP1 as an oncogene in breast cancer models, but tumour suppressive functions have also been reported. Overexpression of YAP1 leads to oncogenic transformation of the immortalised MCF10A human breast cell line [16] and the TEAD-interaction domain of a constitutively active YAP1 $^{\text {S127A }}$ mutant has been shown to promote tumour growth and metastasis of murine mammary carcinoma cell lines [17]. In addition, downregulation of YAP1 in the human breast cancer cell line MCF-7 resulted in decreased cell proliferation and complete loss of tumour formation in mice [18]. Similar results were obtained upon depletion of YAP1 in the basal-like SW527 human breast cancer cell line [19], altogether suggesting YAP1 to function as an oncogene in breast cancer. Furthermore, YAP1 is now widely recognized as one of the oncogenic drivers of 11q22 amplification in liver cancer [20,21] and in many other cancer forms such as ovarian, lung and esophageal squamous cell carcinoma, overexpression of YAP1 is correlated to a worse outcome [22-24].

Despite these reports pointing to YAP1 as an oncogene, the role of YAP1 in breast cancer is far from clear. Yuan and co-authors reported in 2008 that stable downregulation of YAP1 in breast cancer cell lines resulted in protection of anoikis, promotion of anchorage-independent growth and increased migration and invasion. YAP1 depletion resulted in increased tumour growth in nude mice, altogether suggesting a tumour suppressive function of YAP1 in breast cancer [25]. The chromosomal location of the YAP1 gene at $11 \mathrm{q} 22$ is also in favour of it functioning as a tumour suppressor given the frequent loss of heterozygosity $(\mathrm{LOH})$ and deletions of this region in breast cancers [26-30]. In addition, amplification of YAP1 in human breast cancer is infrequent [16] and YAP1 protein expression is often decreased in primary breast cancer [25,31-33]. Therefore, it might be challenging to translate in vitro findings of YAP1 into a clinical setting. To our knowledge, there are no reports concerning the expression of YAP1 and correlations with outcome in subsets of breast cancer patients, hence we set out to investigate and clarify the role of YAP1 in breast cancer.

In this study, we have examined the expression of YAP1 both on protein and gene expression level in a total of 1751 primary breast cancer samples with clinical followup. We show that in ER+ breast cancer, decreased YAP1 expression is associated with more aggressive features such as higher histological grade, increased proliferation and lymph node positivity. In ER- breast cancer the relationship is opposite and increased YAP1 expression correlated to increased proliferation. Furthermore, low YAP1 mRNA expression is independently associated with a worse outcome in the luminal A molecular breast cancer subgroup. We suggest this result relates to a decrease in tamoxifen sensitivity which potentially results from the altered levels of estrogen receptor (ER) and progesterone receptor (PgR) observed upon YAP1 downregulation in the luminal breast cancer cell line T47D.

\section{Methods}

\section{Patient data}

Several patient cohorts were used in this study. The 'screening cohort' consisted of 144 women diagnosed with primary invasive breast cancer at Malmö University Hospital during the years of 2001 and 2002. Ethical permission was obtained from the Lund University Regional Ethics Board and written consent was not required. Median follow-up time for the patients was 5.75 years and median age at diagnosis was 65 years (range 35-97 years). All patients were treated following surgery. This cohort was originally designed as a first-line breast cancer screening cohort for Human Protein Atlas antibodies and further details of the material may be viewed in references [34,35].

The 'randomised cohort' consisted of 564 premenopausal patients presenting with invasive stage II breast cancer who were enrolled in a randomised controlled clinical trial, recruiting between the years of 1986 and 1991. The Lund University and Linköping University Regional Ethics Boards approved the initial randomised study, and there was no requirement for additional consent for the present study. Tumour material was available from 500 patients. The primary aim of the trial was to determine the effect of 2 years of tamoxifen treatment on recurrence-free survival compared to no treatment and patients were included regardless of ER status. Median follow-up time was 13.9 years and further details can be found in reference [36]. Out of the 500 available tumours from the randomised 
cohort, 324 were successfully evaluated for YAP1 expression. Analysis of the missing tumour cores showed a slight correlation to PgR positivity (Spearman's rho 0.105, $\mathrm{p}=$ 0.024), a lower NHG grade (Spearman's rho -0.110, $\mathrm{p}=$ 0.013 ) and a low Ki-67 expression (Spearman's rho -0.122, $\mathrm{p}=0.012$ ). No differences were found in breast cancer recurrences comparing the two groups.

For the gene expression analysis of 1107 primary breast cancers, a meta-analysis of six comprised Affymetrix datasets was performed as previously described [37]. Endpoints for datasets Chin et al., Pawitan et al. and Sotiriou et al. was recurrence-free survival and for Desmedt et al., Ivshina et al. and Wang et al. datasets it was disease-free survival. In this study, we have referred to all endpoints as recurrence-free survival. The Affymetrix U133A probe set ID used for YAP1 was 213342_at. The classification of molecular breast cancer subgroups was made according to the Norway/Stanford signature [37]. Further details of the datasets included in the analysis can be found in references [38-43].

The aCGH (array Comparative Genomic Hybridisation) patient data set consisted of 171 patients with primary operable breast cancer. The dataset is publicly available from NCBI's GEO under the series accession number GSE8757 and further details may be found in reference [44].

\section{Tissue microarray, immunohistochemical staining and} scoring of YAP1 expression

Tumours from the screening and randomised cohorts were assembled in tissue microarrays using a manual tissue arrayer (MTA-1; BeecherInstruments, Inc., Sun Prairie, WI). The pre-treatment process of deparaffinization, rehydration and epitope retrieval of the $4 \mu \mathrm{m}$ sections was carried out using the PT Link module (Dako, Glostrup, Denmark). Staining procedure with YAP1 antibody (1:25, Cell Signaling Technology Inc., Danvers, MA, cat\#4912) was performed using the Autostainer Plus instrument with the Envision Flex programme (Dako). The epitope used for raising the YAP1 antibody includes amino acid 100 (personal communication, Cell Signaling Technology Europe B.V.) and should therefore detect all to date known isoforms of YAP1 [3]. YAP1 was scored as overall intensity as either absent, weak, intermediate or strong by a research associate (SL) and a pathologist (GL). Expression of ER, Ki-67, cyclin D1 and amplification of CCND1 (randomised cohort) had been scored previously in both the randomised and screening cohorts $[35,45,46]$.

\section{Cell culture and transfection}

The human breast cancer cell line T47D (ATCC, Int., Manassas, VA) was maintained in DMEM high glucose medium supplemented with $10 \%$ fetal bovine serum (FBS), $1 \mathrm{mM}$ sodium pyruvate, $2 \mathrm{mM}$ L-glutamine and
1xPEST (streptomycin $90 \mu \mathrm{g} / \mathrm{ml}$, penicillin $90 \mathrm{IU} / \mathrm{ml}$ ). Twenty-four hours before transfection, cells were seeded in PEST-free media which was subsequently replaced by PEST-free serum-free media and siRNA solution (OptiMEM, Gibco, Lipofectamine 2000, Invitrogen Life Technologies, Carlsbad, CA), yielding a final siRNA concentration of $40 \mathrm{nM}$. For negative control, the ON-TARGETplus Non-targeting control siRNA \#2 (\#D001810-02) was used and for targeting YAP1, two different siRNAs were used; ON-TARGETplus YAP1 \#7 (\#J-012 200-07) and ON-TARGETplus YAP1 \#8 (\#J-012200-08) (Dharmacon, Thermo Fisher Scientific Inc., Waltham, MA). After five hours, transfection was discontinued by replacement of medium to regular serum medium.

\section{WST-1 cell viability assay}

The effect of $17 \beta$-estradiol (E2) and 4-OH-tamoxifen was determined by use of WST-1 assay. T47D cells were seeded at a density of 400000 cells in a $60 \mathrm{~mm} \varnothing$ culture dish $\left(28.3 \mathrm{~cm}^{2}\right)$ in PEST-free media and transfected the following day as described. Forty-eight hours after transfection, cells were re-seeded in phenol red-free DMEM supplemented with 5\% charcoal stripped serum in a 96-well plate (5000 cells/well). After an additional 24 hours, cells were incubated at $37^{\circ} \mathrm{C}$ in phenol red-free DMEM supplemented with $1 \%$ charcoal stripped serum with either control treatment (EtOH), 1 nM 17 $\beta$-estradiol (E2) (Sigma \#E2758, Sigma-Aldrich Co, St. Louis, MO) or 1 nM E2 and increasing concentrations of 4-OH-tamoxifen (10 nM, $100 \mathrm{nM}$ and $1 \mu \mathrm{M}$ ) (Sigma \#H7904, SigmaAldrich Co), the active metabolite of tamoxifen, for 4 days. WST-1 assay reagent (Roche Applied Science, Mannheim, Germany) was subsequently added $(10 \mu \mathrm{l})$ to each well and cells were incubated for 4 hours at $37^{\circ} \mathrm{C}$ before the absorbance of each well was measured at the wavelength of $450 \mathrm{~nm}$ and reference wavelength of $690 \mathrm{~nm}$, using a scanning multiwell spectrophotometer (Synergy 2). Statistics were calculated using Student's t-test assuming unequal variances and the mean \pm SD (standard deviation) is presented. Each experiment was measured in triplicate and repeated five times.

\section{Western blotting and immunocytochemistry}

For western blot analysis, cells were scraped in cold PBS and lysed in ice-cold lysis buffer (0.1\% Triton X-100, 0.5\% $\mathrm{NaDOC}, 0.1 \%$ SDS, $50 \mathrm{mM}$ Tris- $\mathrm{HCl} \mathrm{pH}$ 7, $150 \mathrm{mM}$ $\mathrm{NaCl}, 1 \mathrm{mM}$ EDTA, $1 \mathrm{mM} \mathrm{NaF}$ ) supplemented with protease inhibitor cocktail Complete Mini and phosphatase inhibitor cocktail phosSTOP (Roche, Basel, Switzerland). Cell extracts were kept on ice for 30 minutes and vortexed every $10 \mathrm{~min}$ followed by centrifugation at $14000 \mathrm{rpm}$ for $30 \mathrm{~min}$. Supernatants were subsequently collected and protein concentration was determined using the BSA Protein Assay kit (Pierce, Rockford, IL). Twenty $\mu$ g of protein 
were separated on 10\% SDS-PAGE gels and transferred onto nitrocellulose membranes (Hybond ECL, Amersham Pharmacia Biotech, Buckinghamshire, UK). Primary antibodies used included YAP1 (Cell Signaling Technology Inc., Danvers, MA, cat\#4912), cyclin D1 (clone SP4, Dako, Glostrup, Denmark), cyclin A2 (H432, Santa Cruz Biotechnology Inc., Dallas, TX, cat\#sc-751), and actin (I-19, Santa Cruz Biotechnology, Inc., Dallas, TX, cat\#sc-1616). For immunocytochemistry, cells were trypsinised and fixed in $4 \%$ formaldehyde for $30 \mathrm{~min}$ followed by staining with Meyer's haematoxylin for $5 \mathrm{~min}$. Cells were subsequently centrifuged at $1400 \mathrm{rpm}$ for $5 \mathrm{~min}$ and cell pellets were resuspended in $70 \%$ ethanol over night. Cell pellets were dehydrated in graded ethanol series, embedded in paraffin and a cell pellet array was constructed and stained using the following antibodies and dilutions: YAP1 (Cell Signaling Technology Inc., Danvers, MA, 1:25, cat\#4912), ER $\alpha$ (clone 1D5, Dako, Glostrup, Denmark, 1:50, cat\#M 7047) and PgR (clone 636, Dako, 1:1500, cat\#M3569). The experiment was repeated three times and one representative experiment was quantified by automated image analysis.

\section{Luciferase assay}

T47D cells were seeded in a 12-well plate at a density of 100000 cells per well and transfected with siCtr, siYAP1 \#7 or siYAP1 \#8 as described. Forty-eight hours after siRNA transfection, cells were re-transfected with $0.5 \mu \mathrm{g}$ pGL2 luciferase reporter plasmid (pERE-luc) containing the ER binding element ERE (Estrogen Response Element) together with $0.2 \mu \mathrm{g}$ of the Renilla expressing plasmid pRL-TK, which served as an internal control. Five hours later, transfection media was replaced by phenol redfree DMEM, supplemented with 5\% charcoal stripped serum and PEST, and cells were kept in this media 24 hours prior to treatment initiation. Cells were subsequently treated with either $1 \mathrm{nM} 17 \beta$-estradiol (E2) (Sigma \#E2758, Sigma-Aldrich Co, St. Louis, MO) or 1 nM E2 and 100 nM 4-hydroxi-tamoxifen (4-OH-tam) combined (Sigma \#H7904, Sigma-Aldrich Co). Ethanol was used as control treatment, mimicking the amount used for the E2 and E2 + 4-OH-tam wells. After 24 hours of treatment, luciferase activity was measured using the Dual-Luciferase ${ }^{\circ}$ Reporter Assay System (Promega Corporation, Madison, WI) and normalised to the internal control. Three wells were included for each treatment in every experiment $(\mathrm{n}=3)$ and luciferase measurements were made in triplicate.

\section{Statistics}

To examine statistical associations of YAP1 and clinical and molecular parameters, the non-parametric Spearman's rank correlation coefficient test and Mann-Whitney U test were employed. The p-values were not adjusted for multiple testing. Survival analysis was carried out using the KaplanMeier method and recurrence-free survival was compared by means of the log-rank test. The IBM SPSS software program (version 20.0, IBM Corporation, Armonk, NY) was used for calculation.

Statistical significance of differences in tamoxifen response in cell viability experiments (WST-1) and luciferase experiments were calculated using an unpaired two-tailed student's t-test assuming equal variances, unless stated otherwise. Bars indicate the mean of at least three independent experiments and error bars designate \pm SD. Results were considered significant if $\mathrm{p}<0.05$.

\section{Results}

YAP1 protein and mRNA expression in primary breast tumour materials and correlations to clinicopathological and molecular parameters

YAP1 overall protein intensity was scored as either absent, weak, intermediate or strong (Figure 1) in two different primary breast cancer cohorts (screening cohort, $\mathrm{n}=144$ and randomised cohort, $\mathrm{n}=500$ ). YAP1 mRNA expression was also explored using a large gene expression dataset consisting of six previously published primary breast cancer datasets totalling 1107 patients [37]. There were no correlations regarding YAP1 expression and grade, lymph node status or tumour size when including both ER+ and ER- patients in the analysis of the two cohorts and the gene expression dataset (Tables 1, 2 and 3). We next divided our cohorts on the basis of estrogen receptor status. In the ER+ patient group of the screening cohort, an inverse correlation between YAP1 expression and lymph node involvement was observed $(\mathrm{p}=0.022$, Table 1$)$ and in the ER+ subgroup of the randomised cohort, YAP1 expression was negatively correlated to proliferation (measured by Ki-67) and histological grade $(\mathrm{p}=0.016$ and $\mathrm{p}=0.001$ respectively) (Table 2 ). In contrast, in the ER- subgroup of the randomised cohort, a positive correlation between YAP1 expression and proliferation was observed illustrating the importance of performing subgroup analysis $(\mathrm{p}=0.005)$ [see Additional file 1].

Furthermore, YAP1 expression was inversely linked to ER and cyclin D1 expression in all three patient cohorts. When dividing the materials according to ER status, the inverse correlation between YAP1 and cyclin D1 only remained in the ER+ subgroups (Tables 1, 2 and 3, Additional files 1 and 2). In the gene expression dataset, YAP1 mRNA quartiles were positively correlated to tumour size in the ER- subgroup $(\mathrm{p}=0.037)$ [see Additional file 2].

Taken together, in ER+ tumours low YAP1 expression is linked to more clinically aggressive features including grade and proliferation. In ER- tumours the relationship is reversed and high YAP1 expression was linked to more aggressive features. 

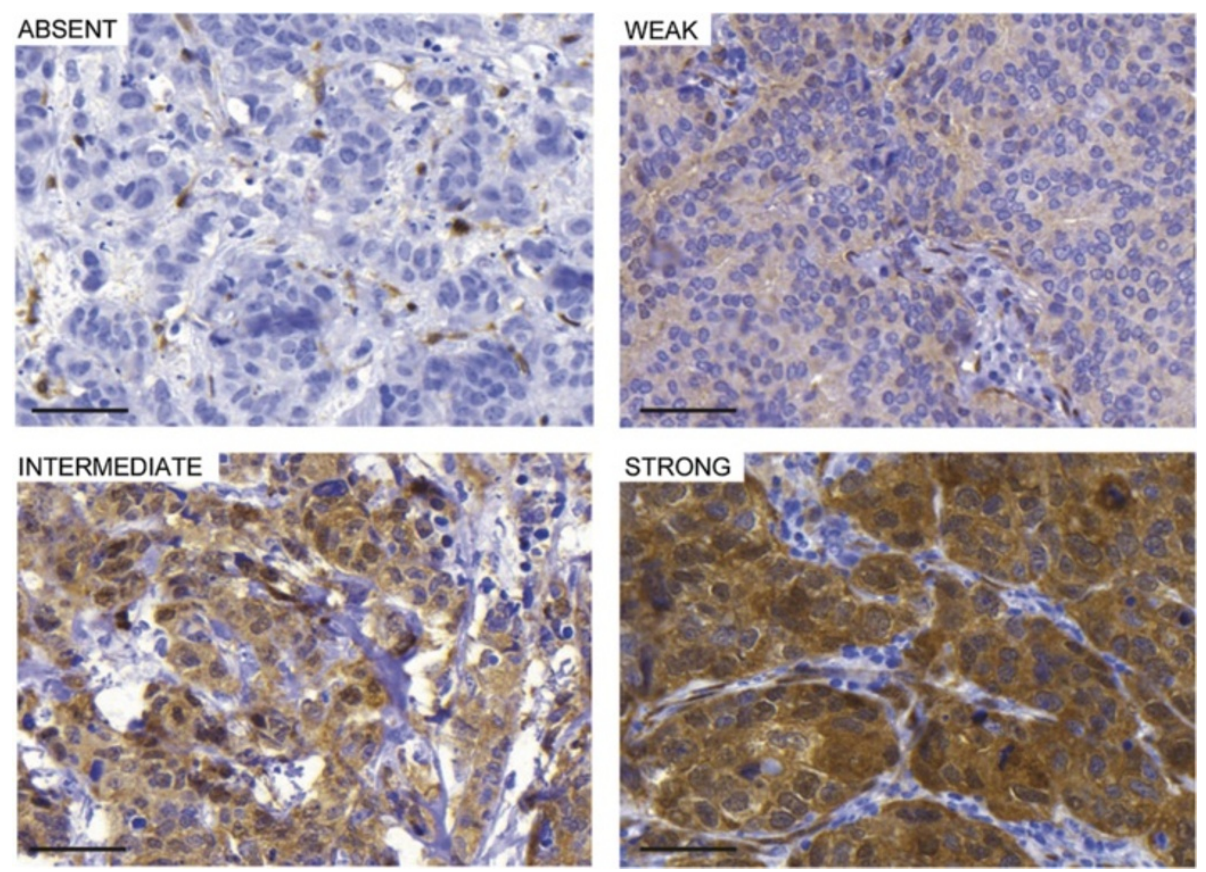

Figure 1 YAP1 staining in primary breast cancers. YAP1 overall intensity was scored as absent, weak, intermediate or strong. Scale bar $=50 \mu \mathrm{m}$.

YAP1 loss and CCND1 amplification are inversely correlated in patient materials

The YAP1 gene is located at $11 \mathrm{q} 22$, a region often deleted upon amplification of the $11 \mathrm{q} 13$ region harbouring the known oncogene cyclin D1 gene (CCND1), which is amplified in $8-15 \%$ of all breast cancers and associated with a worse prognosis [47-49]. The inverse correlation seen between YAP1 and cyclin D1 protein and mRNA expression could be due to a recurring chromosomal rearrangement, resulting in overexpressed cyclin D1 (following amplification) and decreased YAP1 protein expression (following deletion). CCND1 amplification had previously been assessed in the randomised cohort (for further details, see ref [46]) and 9/14 ER+ patients (64\%) with absent YAP1 expression also had amplification of CCND1 (Table 2). However, when removing the CCND1 amplified cases from the analysis, the inverse correlation between YAP1 and cyclin D1 protein expression in the ER+ subgroup remained (Spearman's rho $-0.206, \mathrm{p}=0.030$ ) indicating additional mechanisms for maintaining the negative relationship. This was despite the fact that CCND1 amplified cases were associated with a stronger cyclin D1 expression in this material (data not shown).

The inverse correlation of CCND1 and YAP1 was further examined in an aCGH dataset. Amplification of CCND1 was frequently associated with loss of YAP1 [see Additional file 3]. Nonetheless, amplification of CCND1 was not a prerequisite for $Y A P 1$ gene loss, as there were several tumours with low YAP1 copy number where increased
CCND1 copy numbers were not present [Additional file 3b, lower panel].

To summarise, CCND1 amplification is associated with YAP1 gene loss but the negative association between the proteins is not entirely dependent on chromosomal rearrangements, as the correlation remains after removing cases of CCND1 amplification. Furthermore, YAP1 gene loss may occur independently of CCND1 amplification.

YAP1 mRNA expression holds independent prognostic value In order to investigate the influence of YAP1 expression on disease outcome, survival analyses were performed. In the screening cohort, YAP1 expression was not associated with recurrence-free survival [see Additional file 4]. The gene expression dataset was analysed for recurrence using the median of YAP1 mRNA expression as a cutoff to define groups of high or low YAP1 expression (Figure 2a). Low YAP1 mRNA expression was correlated to a decreased recurrence-free survival and YAP1 mRNA proved to be an independent prognostic factor after adjustment for known prognostic factors such as grade, tumour size and lymph node involvement [see Additional file 5].

As correlations in the screening and randomised patient cohorts implied that YAP1 behaves differently depending on the tumours' expression of ER, recurrence-free survival was analysed in ER+ and ER- subgroups of the gene expression dataset (Figure $2 \mathrm{~b}$ and $\mathrm{c}$ ). In the ER+ subgroup, the two lower quartiles correlated to a shorter recurrence- 
Table 1 Correlations of YAP1 protein expression and clinical and molecular parameters of the screening cohort ( $\mathrm{n}=144)$

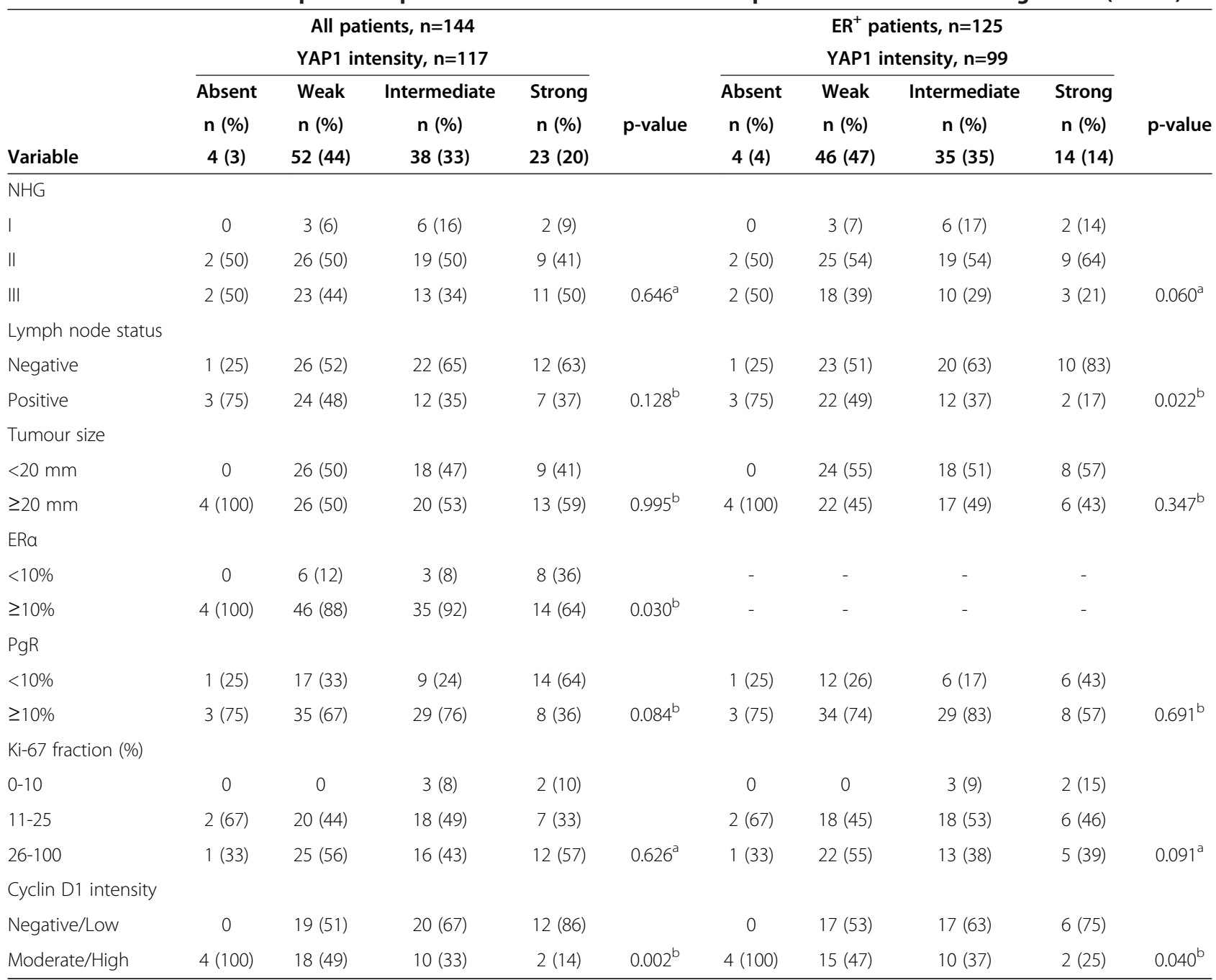

$\mathrm{NHG}=$ Nottingham histological grade, $\mathrm{ER}=$ estrogen receptor, $\mathrm{PgR}=$ progesterone receptor.

aSpearman's rank correlation.

${ }^{\mathrm{b}}$ Mann-Whitney U test.

free survival. Interestingly, in the ER- subgroup the trend was the opposite. Quartiles 2, 3 and 4 were in the bottom of the graph whereas quartile 1 (holding the tumours of lowest YAP1 mRNA expression) demonstrated a remarkably better outcome after 5 years of follow-up, although the trend was not persistent. These results are well in line with the correlations in Tables 1, 2 and 3, implying a contrasting function of YAP1 in breast cancer subgroups.

\section{Low YAP1 mRNA expression is specifically correlated to} worse outcome in the luminal $A$ breast cancer subgroup We further explored if YAP1 mRNA had different significance in regards to outcome in breast cancer molecular subgroups. Strikingly, low YAP1 mRNA was only of importance in the luminal A subtype and of no importance in the remaining four subtypes (luminal B, HER2, basal-like and normal-like) when dividing the dataset accordingly (Figure 2d-h). Subgroup analysis of YAP1 mRNA expression showed that expression was significantly higher in the normal-like and basal-like subgroups compared to the luminal A and B subgroups. However, no statistical difference was found between luminal A and B subgroups [see Additional file 6].

Due to the frequent deletion of the $11 \mathrm{q} 22$ chromosomal region, several genes in close proximity to YAP1 were tested for correlation and outcome in the gene expression dataset [see Additional file 7]. However, YAP1 was the only factor which remained significant of outcome in the multivariate analysis for the luminal A subgroup [see Additional file 8].

In conclusion, decreased YAP1 mRNA expression is a prognostic factor in the luminal A subgroup, independent of a selection of proximal 11q22 genes, cyclin D1 or established prognostic factors. 
Table 2 Correlations of YAP1 protein expression and clinical and molecular parameters of the randomised cohort ( $\mathrm{n}=500$ )

\begin{tabular}{|c|c|c|c|c|c|c|c|c|c|c|}
\hline \multirow[b]{4}{*}{ Variable } & \multirow{2}{*}{\multicolumn{4}{|c|}{$\begin{array}{c}\text { All patients, } n=500 \\
\text { YAP1 intensity, } n=324\end{array}$}} & \multirow{2}{*}{\multicolumn{5}{|c|}{$\begin{array}{c}\mathrm{ER}^{+} \text {patients, } \mathrm{n}=324 \\
\text { YAP1 intensity, } \mathrm{n}=213\end{array}$}} & \multirow{4}{*}{$p$-value } \\
\hline & & & & & & & & & & \\
\hline & $\begin{array}{l}\text { Absent } \\
\mathrm{n}(\%)\end{array}$ & $\begin{array}{l}\text { Weak } \\
\text { n (\%) }\end{array}$ & $\begin{array}{c}\text { Intermediate } \\
\text { n (\%) }\end{array}$ & $\begin{array}{l}\text { Strong } \\
\mathrm{n}(\%)\end{array}$ & \multirow[t]{2}{*}{ p-value } & \multirow{2}{*}{$\begin{array}{l}\text { Absent } \\
\text { n (\%) } \\
21(10)\end{array}$} & \multirow{2}{*}{$\begin{array}{c}\text { Weak } \\
\text { n (\%) } \\
95(45)\end{array}$} & \multirow{2}{*}{$\begin{array}{c}\text { Intermediate } \\
\text { n (\%) } \\
79(37)\end{array}$} & \multirow{2}{*}{$\begin{array}{l}\text { Strong } \\
\text { n (\%) } \\
18(8)\end{array}$} & \\
\hline & $28(9)$ & $130(40)$ & $128(39)$ & $38(12)$ & & & & & & \\
\hline \multicolumn{11}{|l|}{$\mathrm{NHG}$} \\
\hline । & 0 & $10(8)$ & $11(9)$ & $5(13)$ & & 0 & $10(11)$ & $11(14)$ & $5(28)$ & \\
\hline$\|$ & $13(48)$ & $55(44)$ & $56(45)$ & $10(27)$ & & $12(57)$ & $48(50)$ & $51(65)$ & $9(50)$ & \\
\hline III & $14(52)$ & $60(48)$ & $57(46)$ & $22(60)$ & $0.932^{\mathrm{a}}$ & $9(43)$ & $37(39)$ & $16(21)$ & $4(22)$ & $0.001^{\mathrm{a}}$ \\
\hline \multicolumn{11}{|l|}{ Lymph node status } \\
\hline Negative & $7(25)$ & $35(27)$ & $34(27)$ & $15(41)$ & & $5(24)$ & $25(26)$ & $19(24)$ & $5(29)$ & \\
\hline Positive & $21(75)$ & $94(73)$ & $94(73)$ & $22(59)$ & $0.285^{b}$ & $16(76)$ & $70(74)$ & $60(76)$ & $12(71)$ & $0.971^{b}$ \\
\hline \multicolumn{11}{|l|}{ Tumour size } \\
\hline$<20 \mathrm{~mm}$ & $12(44)$ & $43(33)$ & $46(36)$ & $13(34)$ & & $10(50)$ & $35(37)$ & $33(42)$ & $6(33)$ & \\
\hline$\geq 20 \mathrm{~mm}$ & $15(56)$ & $87(67)$ & $82(64)$ & $25(66)$ & $0.815^{b}$ & $10(50)$ & $60(63)$ & $46(58)$ & $12(67)$ & $0.757^{b}$ \\
\hline \multicolumn{11}{|l|}{ ERa } \\
\hline$<10 \%$ & $4(16)$ & $33(26)$ & $46(37)$ & $20(53)$ & & - & - & - & - & \\
\hline$\geq 10 \%$ & $21(84)$ & $95(74)$ & $79(63)$ & $18(47)$ & $<0.001^{\mathrm{b}}$ & - & - & - & - & \\
\hline \multicolumn{11}{|l|}{ PgR } \\
\hline$<10 \%$ & $6(24)$ & $35(29)$ & $47(39)$ & $20(56)$ & & $1(5)$ & $6(7)$ & $4(5)$ & 0 & \\
\hline$\geq 10 \%$ & $19(76)$ & $86(71)$ & $75(61)$ & $16(44)$ & $0.002^{b}$ & $18(95)$ & $84(93)$ & $73(95)$ & $16(100)$ & $0.464^{b}$ \\
\hline \multicolumn{11}{|l|}{ Ki-67 fraction (\%) } \\
\hline $0-10$ & $12(48)$ & $48(40)$ & $53(45)$ & $10(29)$ & & $9(47)$ & $37(42)$ & $47(64)$ & $9(56)$ & \\
\hline $11-25$ & $7(28)$ & $38(32)$ & $34(29)$ & $7(20)$ & & $6(32)$ & $30(34)$ & $20(27)$ & $3(19)$ & \\
\hline $26-100$ & $6(24)$ & $34(28)$ & $31(26)$ & $18(51)$ & $0.198^{\mathrm{a}}$ & $4(21)$ & $21(24)$ & $6(8)$ & $4(25)$ & $0.016^{\mathrm{a}}$ \\
\hline \multicolumn{11}{|l|}{ Cyclin D1 intensity } \\
\hline absent/weak & $8(31)$ & $67(53)$ & $81(67)$ & $29(76)$ & & $3(14)$ & $39(42)$ & $40(51)$ & $9(50)$ & \\
\hline intermediate/strong & $18(69)$ & $59(47)$ & $40(33)$ & $9(24)$ & $<0.001^{\mathrm{b}}$ & $18(86)$ & $54(58)$ & $38(49)$ & $9(50)$ & $0.010^{b}$ \\
\hline \multicolumn{11}{|l|}{ CCND1 amplification } \\
\hline No & $8(44)$ & $69(84)$ & $75(89)$ & $24(96)$ & & $5(36)$ & $48(80)$ & $47(84)$ & $12(92)$ & \\
\hline Yes & $10(56)$ & $13(16)$ & $9(11)$ & $1(4)$ & $<0.001^{\mathrm{b}}$ & $9(64)$ & $12(20)$ & $9(16)$ & $1(8)$ & $0.003^{b}$ \\
\hline
\end{tabular}

NHG=Nottingham histological grade, $\mathrm{ERa}=$ estrogen receptor, $\mathrm{PgR}=$ progesterone receptor.

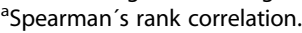

${ }^{\mathrm{b}}$ Mann-Whitney $\mathrm{U}$ test.

\section{Absence of YAP1 protein expression in primary breast tumours is linked to an impaired tamoxifen response} The prominent effect of decreased YAP1 mRNA in the luminal A subtype led us to hypothesize that YAP1 could be important for the response to endocrine therapies. The majority of luminal A classified tumours are $\mathrm{ER}+$ and hence treated with some variant of endocrine targeting treatment such as tamoxifen. To study the possible effect of YAP1 loss on tamoxifen response, recurrence-free survival was analysed in the randomised cohort, as this patient material originates from a clinical trial evaluating tamoxifen response in a randomised setting. Significance of YAP1 expression was initially analysed in ER+ and ER- subgroups, as molecular subgroup data was not available for this cohort. Figure 3a, which included both treated and untreated ER+ patients, showed significantly decreased recurrence-free survival when YAP1 expression was absent. In the ER- subgroup, both absent and strong YAP1 expression correlated to a worse outcome (Figure $3 \mathrm{~b})$. ER+ patients were then divided according to whether they received tamoxifen or control treatment (Figure 3c and d). YAP1 expression was not correlated to outcome in the untreated ER+ patient subgroup whereas there were significant differences in outcome in the tamoxifen treated ER+ subgroup. Figure $3 e$ and $f$ specifically address the tamoxifen response. ER+ patients with tumours of YAP1 expression scored as either weak, intermediate or strong (score 1-3) did significantly better 
Table 3 Correlations of YAP1 mRNA expression and clinical and molecular parameters of the gene expression dataset $(n=1107)$

\begin{tabular}{|c|c|c|c|c|c|c|c|c|c|c|}
\hline \multirow[b]{4}{*}{ Variable } & \multirow{2}{*}{\multicolumn{4}{|c|}{$\begin{array}{l}\text { All patients, } \mathrm{n}=1107 \\
\text { YAP1 mRNA Quartiles }\end{array}$}} & \multirow{2}{*}{\multicolumn{5}{|c|}{$\begin{array}{l}\text { ER+ patients, } n=700 \\
\text { YAP1 mRNA Quartiles }\end{array}$}} & \multirow[b]{4}{*}{$\mathrm{p}$-value } \\
\hline & & & & & & & & & & \\
\hline & Q1 & Q2 & Q3 & Q4 & \multirow[b]{2}{*}{ p-value } & Q1 & Q2 & Q3 & Q4 & \\
\hline & $\mathrm{n}=277(\%)$ & $\mathrm{n}=276(\%)$ & $n=277(\%)$ & $\mathrm{n}=277(\%)$ & & $n=175(\%)$ & $n=175(\%)$ & $n=175(\%)$ & $n=175(\%)$ & \\
\hline \multicolumn{11}{|l|}{$\overline{\mathrm{NHG}}$} \\
\hline । & $29(15)$ & $43(24)$ & $46(24)$ & $49(24)$ & & $17(15)$ & $34(31)$ & $33(28)$ & $38(30)$ & \\
\hline$\|$ & $94(47)$ & $79(43)$ & $77(40)$ & $80(38)$ & & $60(51)$ & $48(44)$ & $54(46)$ & $48(37)$ & \\
\hline III & $77(38)$ & $61(33)$ & $69(36)$ & $80(38)$ & $0.355^{\mathrm{a}}$ & $40(34)$ & $27(25)$ & $31(26)$ & $42(33)$ & $0.165^{\mathrm{a}}$ \\
\hline \multicolumn{11}{|c|}{ Lymph node status } \\
\hline Negative & $187(81)$ & $207(87)$ & $194(80)$ & $192(85)$ & & $138(80)$ & $155(89)$ & $139(81)$ & $138(79)$ & \\
\hline Positive & $44(19)$ & $31(13)$ & $47(20)$ & $35(15)$ & $0.715^{b}$ & $34(20)$ & $20(11)$ & $32(19)$ & $36(21)$ & $0.433^{b}$ \\
\hline \multicolumn{11}{|c|}{ Tumour size } \\
\hline$<20 \mathrm{~mm}$ & $78(48)$ & $85(54)$ & $93(54)$ & $82(48)$ & & $55(45)$ & $59(52)$ & $72(59)$ & $76(56)$ & \\
\hline$\geq 20 \mathrm{~mm}$ & $86(52)$ & $72(46)$ & $78(46)$ & $88(52)$ & $0.917^{b}$ & $66(55)$ & $54(48)$ & $50(41)$ & $59(44)$ & $0.056^{b}$ \\
\hline \multicolumn{11}{|l|}{ ERa } \\
\hline$<10 \%$ & $44(19)$ & $57(24)$ & $56(23)$ & $82(36)$ & & - & - & - & - & \\
\hline$\geq 10 \%$ & $188(81)$ & $180(76)$ & $187(77)$ & $145(64)$ & $<0.001^{b}$ & - & - & - & - & \\
\hline \multicolumn{11}{|c|}{ PgR Quartiles } \\
\hline Q1 & $66(24)$ & $62(22)$ & $60(22)$ & $89(32)$ & & $51(29)$ & $45(26)$ & $36(21)$ & $43(25)$ & \\
\hline Q2 & $82(30)$ & $76(28)$ & $60(22)$ & $59(21)$ & & $49(28)$ & $48(27)$ & $41(23)$ & $37(21)$ & \\
\hline Q3 & $76(27)$ & $70(25)$ & $71(25)$ & $60(22)$ & & $40(23)$ & $43(25)$ & $48(27)$ & $44(25)$ & \\
\hline Q4 & $53(19)$ & $68(25)$ & $86(31)$ & $69(25)$ & $0.836^{\mathrm{a}}$ & $35(20)$ & $39(22)$ & $50(29)$ & $51(29)$ & $0.011^{a}$ \\
\hline \multicolumn{11}{|c|}{ Cyclin D1 Quartiles } \\
\hline Q1 & $57(20)$ & $73(26)$ & $66(24)$ & $81(29)$ & & $31(18)$ & $45(26)$ & $51(29)$ & $48(27)$ & \\
\hline Q2 & $41(15)$ & $63(23)$ & $87(31)$ & $85(31)$ & & $26(15)$ & $47(27)$ & $53(30)$ & $49(28)$ & \\
\hline Q3 & $69(25)$ & $69(25)$ & $78(28)$ & $61(22)$ & & $47(27)$ & $33(19)$ & $44(25)$ & $51(29)$ & \\
\hline Q4 & $110(40)$ & $71(26)$ & $46(17)$ & $50(18)$ & $<0.001^{\mathrm{a}}$ & $71(41)$ & $50(28)$ & $27(16)$ & $27(16)$ & $<0.001^{\mathrm{a}}$ \\
\hline
\end{tabular}

NHG=Nottingham Histological Grade, ER=Estrogen receptor, PgR=Progesterone receptor.

aSpearman's rank correlation.

${ }^{\mathrm{b}}$ Mann-Whitney $\mathrm{U}$ test.

when treated with tamoxifen compared to no treatment. In the group of patients with tumours of absent YAP1 expression (score 0 ), there was no difference in outcome between the control and tamoxifen group. A multivariate interaction analysis further demonstrated a statistically significant association between absent YAP1 and an impaired response to tamoxifen $(\mathrm{p}=0.042$, Table 4$)$. These results suggest YAP1 as a predictive marker for tamoxifen response.

YAP1 downregulation in the luminal cell line T47D results in a weaker tamoxifen response

The T47D cell line was chosen to further investigate the role of YAP1 in tamoxifen response due to its relatively high expression of YAP1 compared to other luminal cell lines such as MCF-7, and also since proliferation in this cell line is not significantly affected by YAP1 downregulation [see Additional file 9] [18,50]. YAP1 was transiently downregulated followed by treatment with $17 \beta$-estradiol (E2) or E2 and increasing concentrations of 4-OH-tamoxifen. Cell viability was subsequently evaluated by means of WST-1 assay. YAP1 protein levels were efficiently downregulated and maintained at a depleted level even after 4 days of treatment (Figure 4a). There were no notable differences in the expression of the cell cycle proteins cyclin D1 and cyclin A2 when YAP1 was downregulated, although a slight decrease in cyclin A2 was noted in the $\mathrm{EtOH}$ control treated cells following YAP1 silencing (Figure 4a), compared to siCtr cells. To evaluate tamoxifen response, cell viability fold change was calculated comparing different concentrations of tamoxifen to estrogen stimulation, within a cell population treated with a specific siRNA (Figure 4b). Both siCtr and siYAP1 \#7 demonstrated significant changes in cell viability upon addition of $10^{-7} \mathrm{M} 4-\mathrm{OH}$-tamoxifen, 


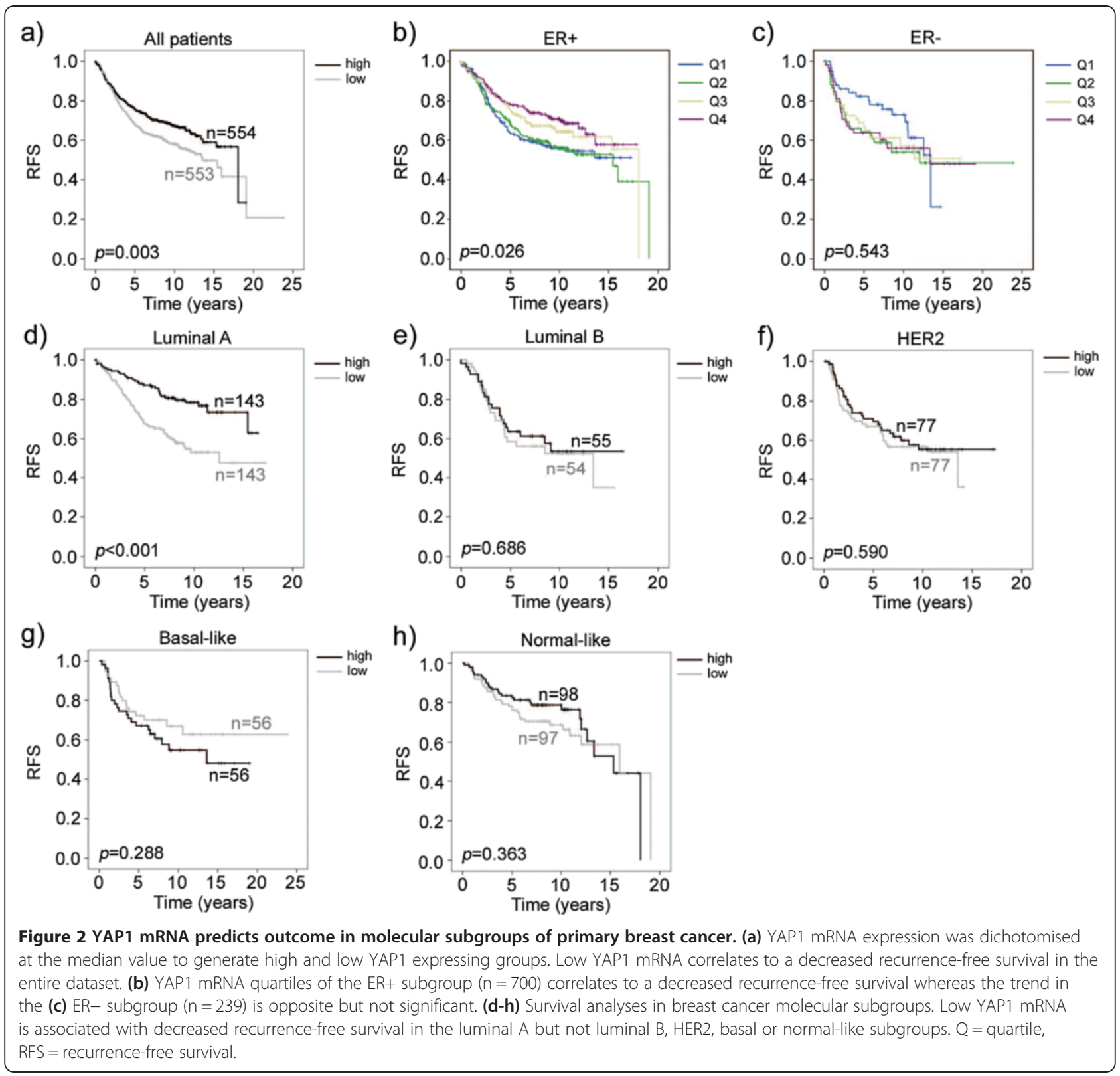

whereas for siYAP1 \#8, 4-OH-tamoxifen had no significant effect until the concentration of $10^{-6} \mathrm{M}$ was reached. SiCtr treated cells responded significantly better to rising concentrations of 4-OH-tamoxifen $(\mathrm{p}=0.006)$ whereas siYAP \#7 and $\# 8$ showed no such dependence $(\mathrm{p}=0.09$ and $\mathrm{p}=0.10$, respectively).

To more specifically address the activity of ER, a luciferase assay measuring the activation of the estrogen response element (ERE) was employed. T47D cells were first transfected with siCtr, siYAP1 \#7 or siYAP1 \#8 followed by a pERE-luciferase construct transfection, and treated with E2 or a combination of E2 and 4-OH-tamoxifen for 24 hours (Figure 4c). Downregulation of YAP1 resulted in a less efficient tamoxifen-induced inhibition of ER activity, where siCtr cells showed a 4.52 fold decrease compared to only 3.33 and 3.79 for siYAP1 \#7 and \#8 cells, respectively.

To summarise, although a response to tamoxifen was still measurable, downregulation of YAP1 in the T47D cell line resulted in a later and less efficient tamoxifen response.

\section{Downregulation of YAP1 results in increased ER and PgR protein levels}

As ER and PgR protein expression are of great importance in predicting response to tamoxifen [51], T47D cell pellets (siCtr, siYAP1 \#7 and \#8) treated with EtOH, E2 or E2 and 4-OH-tamoxifen combined were examined for ER and PgR protein expression by immunocytochemistry 

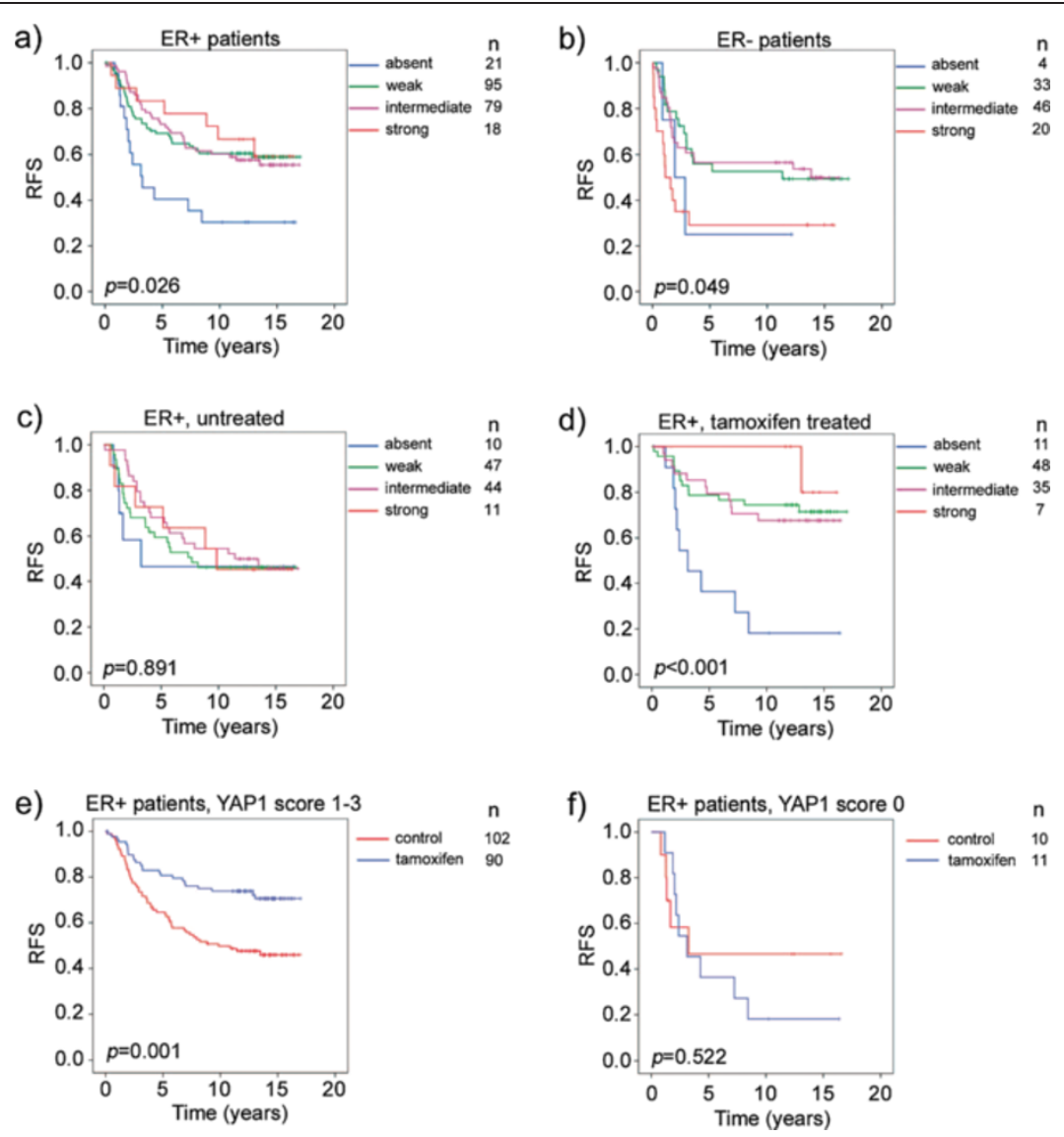

Figure 3 Absence of YAP1 protein expression is associated with tamoxifen resistance in the randomised patient cohort. (a) Kaplan-Meier analysis of all ER+ patients, both treated (tamoxifen) and untreated. Absent YAP1 expression is correlated to a decreased recurrence-free survival. (b) In the ER- subgroup both absent and strong YAP1 expression correlated to a worse outcome. (c) Analysis of the untreated patient cohort of ER+ patients indicates no prognostic value of YAP1. (d) Analysis of the tamoxifen treated patient cohort of ER+ patients suggests predictive value of absent YAP1. (e) ER+ patients with tumours scored as weak, intermediate or strong YAP1 expression do significantly better when treated with tamoxifen compared to the untreated control group whereas (f) ER+ patients with YAP1 scored as absent do not benefit from tamoxifen. RFS = recurrence-free survival.

(Figure 5). The knockdown of YAP1 was not 100\% complete but the increase of YAP1 protein expression seen in siCtr cells upon E2 stimulation was effectively inhibited in siYAP\#7 and \#8 cells. Interestingly, siYAP1 \#7 and \#8 displayed a strong overall increase in PgR intensity, even in control treated (EtOH) cells. The decrease of PgR in 4$\mathrm{OH}$-tamoxifen treated siCtr cells was not as evident in siYAP1 \#7 and \#8 cells. As previously reported, ER is downregulated upon E2 treatment, an effect antagonised by tamoxifen which stabilises ER [52]. Although this effect

Table 4 The difference in treatment response between patient groups of different YAP1 expression is significant: A multivariate Cox proportional hazards regression analysis for YAP expression and treatment interaction based on ER+ breast cancer patients*

\begin{tabular}{|c|c|c|c|c|}
\hline \multirow[b]{2}{*}{ Variable } & \multirow[b]{2}{*}{ Category } & \multicolumn{2}{|c|}{ Recurrence-free survival } & \multirow[b]{2}{*}{$P$ value } \\
\hline & & $\mathrm{HR}$ & $95 \% \mathrm{Cl}$ & \\
\hline \multirow[t]{2}{*}{ YAP1 expression } & Weak, intermediate or strong & 1.00 & & \\
\hline & Absent & 1.42 & 0.56 to 3.59 & 0.456 \\
\hline \multirow[t]{2}{*}{ Treatment } & Control & 1.00 & & \\
\hline & Tamoxifen & 0.42 & 0.26 to 0.68 & $<0.001$ \\
\hline Interaction variable ${ }^{\dagger}$ & Tamoxifen x YAP1 expression & 3.51 & 1.05 to 11.75 & 0.042 \\
\hline
\end{tabular}

*Other factors included in the analysis are tumour grade (NHG I + II vs. III), nodal status (negative vs. positive) and tumor size ( $\leq 20 \mathrm{~mm}$ vs. $>20 \mathrm{~mm}$ ). ${ }^{\dagger}$ Interaction variable states if there is a difference in the treatment response in relation to YAP1 expression.

$\mathrm{HR}=$ Hazard ratio, $\mathrm{Cl}=$ Confidence interval, $\mathrm{NHG}=$ Nottingham histological grade . 
a)

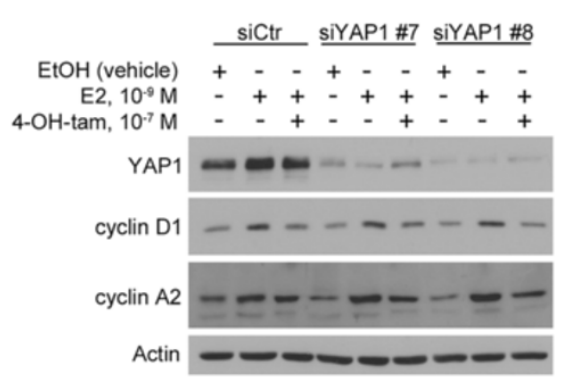

c)

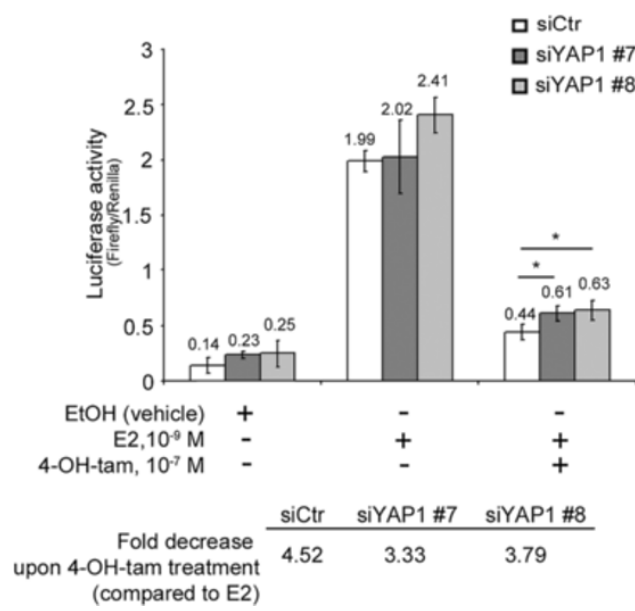

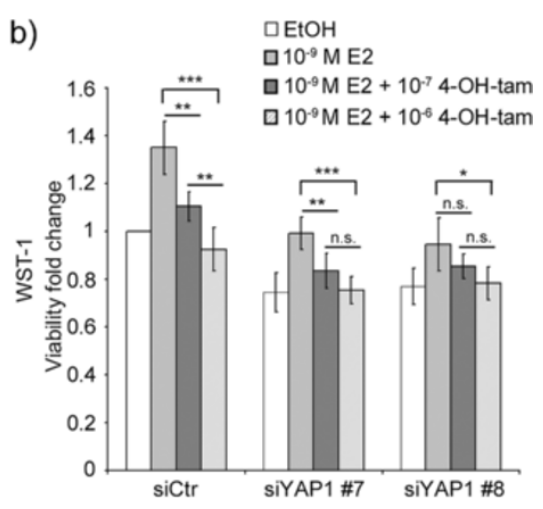

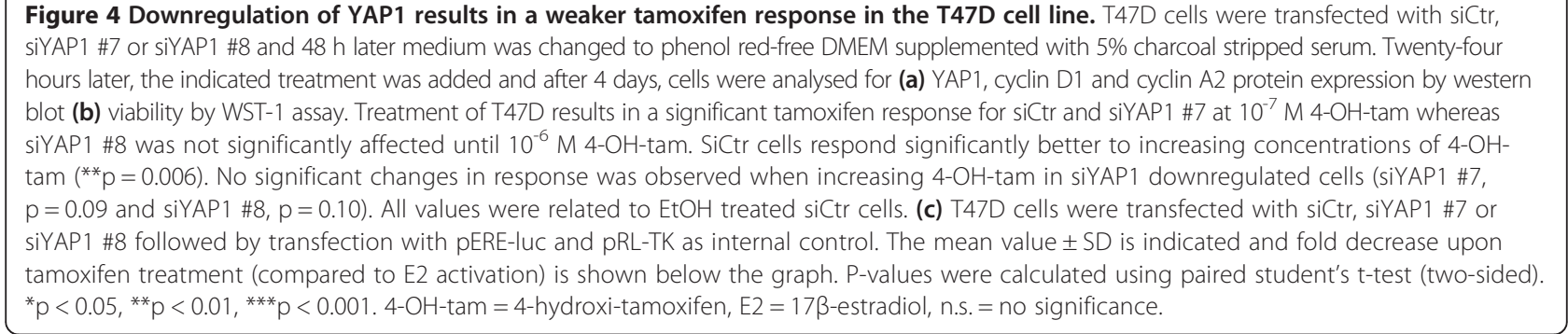

was seen in all siRNA treatments, the expression of ER was higher overall in siYAP \#7 and \#8. Taken together, downregulation of YAP1 increased the level of hormone receptors, indicating deregulation of hormone receptor signalling when YAP1 is decreased.

\section{Discussion}

In this study, we have shown that decreased mRNA levels of YAP1 independently predict outcome in ER+ and more specifically, luminal A breast cancers. This subgroup specificity led us to hypothesize that YAP1 is of importance in the response to endocrine treatments used to target the estrogen receptor, such as the widely used anti-estrogen tamoxifen. By examining a premenopausal primary breast tumour material randomised to either tamoxifen or control treatment, we found that absent YAP1 protein expression was associated with impaired tamoxifen response. Although effects were small, downregulation of YAP1 in a luminal breast cancer cell line resulted in a weaker tamoxifen response as measured by cell viability and activity of the estrogen receptor. In addition, silencing of YAP1 resulted in increased protein levels of ER and PgR, indicating increased signalling and deregulation of the ER pathway, a possible mechanism for the weaker tamoxifen response in this cell line.

The role of YAP1 in breast cancer is at present a matter of debate. By placing the protein in the context of estrogen receptor positive or negative disease, some reported results which appear contradictory may be explained. In 2006, Overholtzer et al. published a report on the oncogenic 


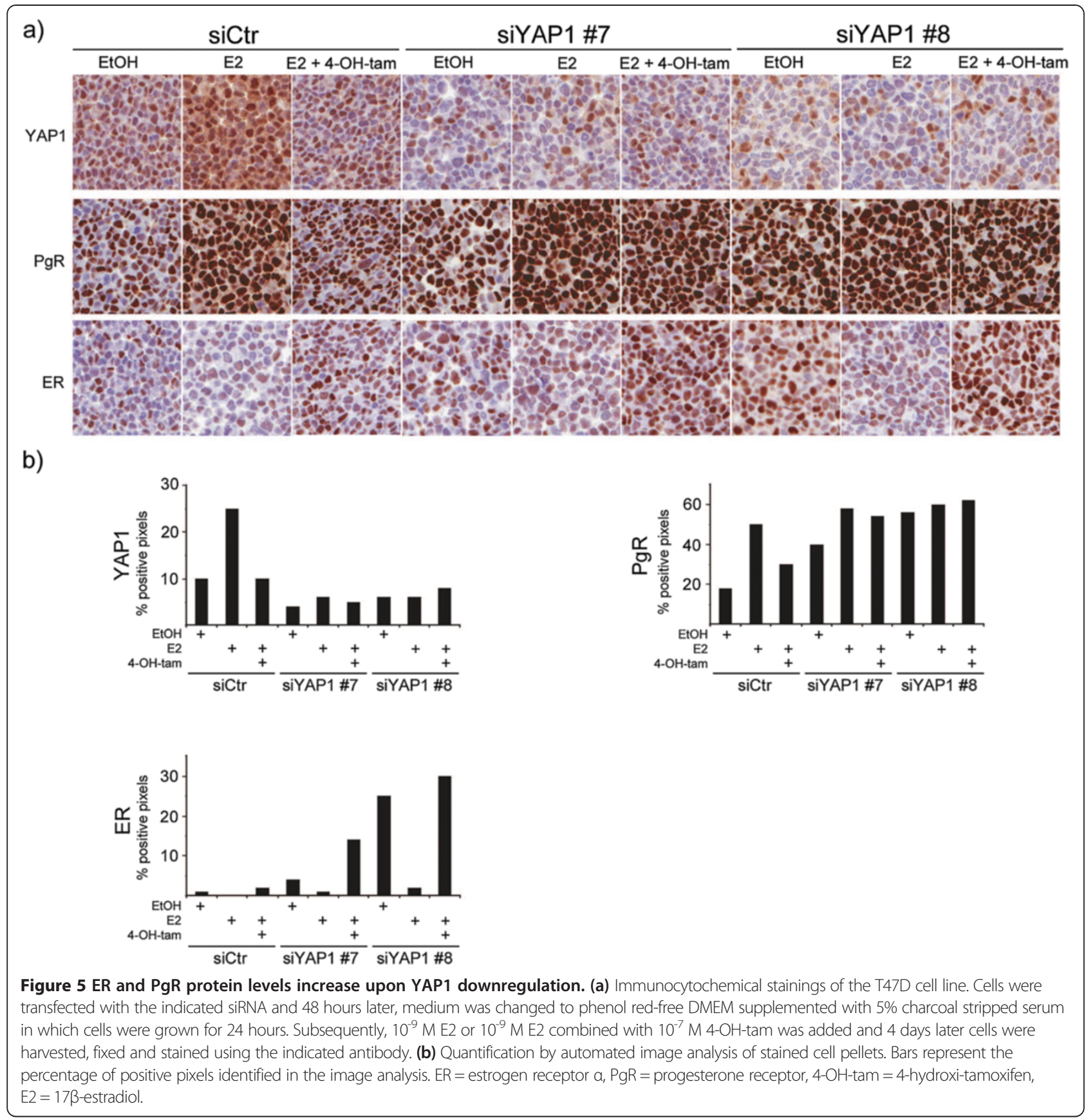

properties of YAP1, which had been identified through a screen for copy number changes in mouse mammary tumours. Interestingly, the genetic background used for screening was the Brca1/Trp-53 which in the majority of cases gives rise to ER- mammary tumours of high grade [53]. The normal cell line subsequently used for transformation experiments was MCF-10A, reported to be ER- [54], altogether suggesting a possible function of YAP1 as an oncogene in ER- breast cancer. This is in support of our results where strong YAP1 expression was associated with increased proliferation in ER- tumours [see Additional file 1]. Furthermore, YAP1 was recently reported to function as an oncogene by promoting proliferation and survival of breast cancer cells by binding and stabilising the KLF5 (Kruppel-like factor 5) transcription factor through its PPxY motif [19]. KLF5 and YAP1 were reported to be predominately expressed in ER- cell lines and all experimental data was obtained from ER- breast cancer cell lines. Activation of YAP1 in the ER- cell line SUM159 [55] mediated by LIFR (leukemia inhibitory factor receptor) repression resulted in substantial lung metastases in nude mice, again suggesting an oncogenic role of YAP1 in ER- breast 
cancer [56]. The fundamental differences on the transcriptomic level of ER+ and ER- breast cancers is long established [57], and our results indicate that subgroup analysis is critical for the translational understanding of YAP1 in breast disease. There are however also reports where YAP1 show oncogenic features in ER+ breast cancer models. For example, stable knockdown of YAP1 in the ER+ human breast cancer cell line MCF-7 resulted in complete loss of tumour formation in BALB/c nude mice [18]. As YAP1 knockdown significantly decreased proliferation in MCF-7 cells, the negative result in tumour formation was perhaps expected. In the randomised breast cancer material studied here, decreased YAP1 expression was associated with increased proliferation in ER+ breast cancers (Table 2), indicating a discrepancy between the ER+ cell line model and primary breast cancer data. The effects of protein downregulation in cell line models are usually assessed after days or weeks, whereas primary tumours evolve during a period of years. As YAP1 loss is proposed to be an early event in breast cancer [25], YAP1 downregulation in cell lines such as MCF-7 might have to be assessed at much later time points in order to better correlate findings between primary tumour data and cell lines. The microenvironment might also constitute a critical parameter for understanding and modelling YAP1 in breast cancer, and stable downregulation of YAP1 in MCF-7 has been reported to result in increased invasion in a matrigel transwell assay [25].

The notion of YAP1 functioning as a tumour suppressor in breast cancer was first proposed by Yuan et al. in 2008 [25]. The 11q22 region where the YAP1 gene is located is a frequent site of LOH (loss of heterozygosity) in breast cancer [26-30] and Yuan et al. reported that half of tumours negative for YAP1 staining also had specific $\mathrm{LOH}$ at the YAP1 gene locus. This indicates $11 \mathrm{q} 22$ deletions as part of the explanation to the recurrent decreased YAP1 protein levels in breast cancer, but also supports the possibility of additional unknown mechanisms contributing to YAP1 protein loss in breast cancer [25,31-33]. Furthermore, downregulation of YAP1 was shown to increase anoikis, migration and invasion, altogether suggesting a tumour suppressive function for YAP1 [25]. In our study, YAP1 expression was not informative of outcome in the untreated ER+ subgroup of the randomised cohort (Figure 3c) which might be expected if YAP1 had had true tumour suppressive properties. In the ER+ tamoxifen treated subgroup, there were great differences in outcome depending on YAP1 expression (Figure 3d). Altogether, these results suggest YAP1 to function as a treatment predictive factor in ER+ breast cancer, rather than a prognostic factor for the natural disease progression.

CCND1 amplification has previously been linked to a poor tamoxifen response, however cyclin D1 protein expression could not predict response as efficiently as the amplification event [46]. This indicates additional events affecting tamoxifen response associated with CCND1 amplification. Co-amplification of other 11q13 genes is most likely of importance, but deletions of distal 11q might also contribute to tamoxifen resistance [58] and YAP1 is a likely candidate considering the data presented herein. CCND1 amplified breast tumours have been reported to display loss of the distal part of $11 \mathrm{q}$ in $70 \%$ of cases [59]. However, the inverse correlation of cyclin D1 and YAP1 protein expression observed in the randomised tumour material remained after removing the $C C N D 1$ amplified cases from the analysis, indicating additional functions for maintaining the negative relationship between the two proteins. Also, it has been reported that loss of distal 11q may occur independently of 11q13 amplification [26] as shown in [Additional file 3b] where YAP1 loss is present independently of CCND1 amplification in several cases (red arrows). Hence, our results suggest that loss of YAP1 may confer aggressiveness in ER+ breast cancers independently of the established oncogenic CCND1 amplification.

The differences in correlations between the two patient cohorts might partly be explained by dissimilarities of the cohorts. The randomised patient cohort only included premenopausal patients with stage II breast cancer which renders this a more defined group compared to the screening cohort, where all patients with breast tumours defined as invasive was included. In the much smaller screening cohort, only four patients were assessed to have absent YAP1 protein expression, challenging the analysis since the complete loss of YAP1 appeared to be the conclusive factor on protein level. The conformity in treatment of the randomised cohort was further valuable for investigating the effect of YAP1 on tamoxifen response, whereas patients in the screening cohort were treated according to guidelines.

YAP1 has previously been reported to be able to enhance the hormone dependent activation of ER and PgR by acting as a coactivator through direct interaction with WW domain binding protein-2, WBP-2 [60]. The coactivation function of YAP1 was shown to be strictly dependent on the presence of WBP-2 which binds the estrogen receptor in a complex with E6-AP (E6-associated protein) upon E2 stimulation. From this perspective, downregulation of YAP1 would potentially lead to a decreased activation of ER in our experimental setting. Instead, the trend is an increase in ER signalling upon YAP1 downregulation illustrated by the increase in PgR protein levels in Figure 5, given that $\mathrm{PgR}$ is a known target gene of E2 signalling [61]. Interestingly, stabilisation of PgR has previously been shown to be important in Brca1-mediated tumorigenesis $[62,63]$. Also, no effect was observed on the E2 dependent activation of the Estrogen Responsive Element (ERE) upon depletion of YAP1. If any effect, the activity of the ERE is increased (siYAP1 \#8, Figure 4c). 
In vitro experiments downregulating YAP1 in the luminal A classified T47D cell line resulted in a weaker response to tamoxifen as measured by cell viability. There were several reasons for choosing the T47D cell line for the modelling of tamoxifen response. First, T47D cells have a higher gene and protein expression of YAP1 compared to other luminal breast cancer cell lines such as MCF-7, making the T47D cell line more suitable for YAP1 downregulating experiments [see Additional file 9c] $[18,50]$. Second, T47D cells are not as reliant on YAP1 for proliferation as MCF-7 cells [see Additional file 9a and b] which also favours the selection of the T47D cell line. In Figure $4 \mathrm{~b}$, the two siRNAs targeting YAP1 show somewhat diverging results where siYAP1 \#7 resulted in a significant tamoxifen response already at treatment of $10^{-7} \mathrm{M}$ 4-OH-tamoxifen, but siYAP1 \#8 did not reach significance until a 10-fold higher tamoxifen concentration was used. Also, increasing concentrations of 4-OHtamoxifen in siCtr-treated cells resulted in a more effective inhibition of cell viability. This effect could not be observed upon YAP1 depletion, in support of YAP1 being important for the 4-OH-tamoxifen effect. The general negative effect of YAP1 downregulation on cell viability somewhat complicates the interpretation of the result, however when measuring the specific activity of the estrogen response element upon E2 stimulation with or without YAP1, similar results were obtained. The fold decrease resulting from 4-OH-tamoxifen inhibition was less prominent when YAP1 was downregulated (siYAP1 3.33-3.79 vs. siCtr 4.52), indicating a role for YAP1 in mediating inhibition of ERE activity. The small but significant effect implies additional mechanisms contributing to YAP1's role in tamoxifen resistance; for example, the known estrogen target gene cyclin D1 does not have an ERE promoter element, instead a cAMP response like element is suggested to be critical in mediating the transcriptional activation of the cyclin D1 gene upon E2 stimulation [64]. Possibly, measurement of cAMP response like element activation in a similar setting as described would yield additional support for the involvement of YAP1 in ERmediated transcription.

\section{Conclusion}

By analysing YAP1 mRNA and protein expression in a large number of primary breast tumours, we show that increased YAP1 is associated with more aggressive tumours in ER- breast tumours whereas in ER+ tumours, decreased YAP1 expression correlates to aggressiveness. These results clearly indicate the necessity of analysing ER+ and ER- breast tumours separately regarding YAP1 expression. Furthermore, low YAP1 mRNA expression was significantly associated with a decreased recurrencefree survival in the luminal A breast cancer subgroup, independently of lymph node status or proximal, possibly co-deleted 11q22 genes. This indicates a specific role for YAP1 in predicting outcome in this subgroup. Absent YAP1 protein expression was shown to be linked to an impaired tamoxifen response in a randomised patient material and in vitro experiments of YAP1 downregulation resulted in decreased sensitivity to tamoxifen, together with an increase in ER and PgR protein levels. Further research is warranted to elucidate the exact mechanism on YAP1 mediating endocrine resistance and its possible use as a marker in predicting response to tamoxifen.

\section{Additional files}

\section{Additional file 1: Correlations of YAP1 protein expression and clinical and molecular parameters of the ER-subgroup of the randomised cohort. \\ Additional file 2: Correlations of YAP1 mRNA expression and clinical and molecular parameters of the ER- subgroup of the gene expression dataset. \\ Additional file 3: CCND1 amplification and YAP1 loss are inversely correlated on gene level.}

Additional file 4: Kaplan-Meier analysis of the screening cohort. (a) YAP1 expression does not predict outcome in all patients ( $p=0.342$, log-rank test) or in (b) the subgroup of ER+ patients ( $p=0.948$, log-rank test).

Additional file 5: Cox multivariate regression analysis in the gene expression dataset. YAP1 mRNA expression is an independent prognostic factor after adjustment of known prognostic factors. Additional file 6: YAP1 mRNA expression in breast cancer molecular subgroups of the gene expression dataset $(n=1107)$.

Additional file 7: Correlations of YAP1 mRNA and a selection of genes located at the same gene region as YAP1; $11 \mathrm{q} 22$.

Additional file 8: Cox uni- and multivariate analysis based on the gene expression dataset and the genes selected from Additional file 7.

Additional file 9: Growth curves of T47D and MCF-7 upon YAP1 downregulation and protein expression levels of YAP1 in breast cancer cell lines.

Abbreviations

YAP1: Yes-associated protein; ER: Estrogen receptor a; PgR: Progesterone receptor; ERE: Estrogen responsive element; ER+: Estrogen receptor a positive; ER-: Estrogen receptor a negative.

\section{Competing interests}

The authors declare that they have no competing interests.

\section{Authors' contributions}

SL analysed YAP1 protein expression, performed statistical analyses of protein and gene expression data, designed and performed experiments and wrote the manuscript. NPT and AHS performed gene expression data analyses and critically revised the manuscript. $\mathrm{KJ}$ and OS participated in the design of the study, provided study material and information of patients, and revised the manuscript. HA designed experiments, analysed and interpreted data and critically revised the manuscript. GL participated in the design of the study, analysed and interpreted data, performed statistical analyses, analysed YAP1 protein expression and revised the manuscript. All authors read and approved the final manuscript.

\section{Acknowledgements}

The authors thank Elise Nilsson for excellent technical support. We are very grateful to Breakthrough Breast Cancer, the Swedish Cancer Society and Malmö University Hospital Research and Cancer Funds for funding. 


\section{Author details}

'Center for Molecular Pathology, Department of Laboratory Medicine, Lund University, Skåne University Hospital, 20502 Malmö, Sweden. ${ }^{2}$ Cancer Center Karolinska, Karolinska Institutet and University Hospital, 17176 Stockholm, Sweden. ${ }^{3}$ Applied Bioinformatics of Cancer, University of Edinburgh Cancer Research Centre, Carrington Crescent, Edinburgh EH4 2XR, UK. ${ }^{4}$ Division of Oncology, Department of Clinical and Experimental Medicine, Faculty of Health Sciences, Linköping University, Linköping, Sweden. ${ }^{5}$ Department of Clinical Sciences, Division of Pathology, Lund University, Skåne University Hospital, 22185 Lund, Sweden. ${ }^{6}$ Translational Cancer Research, Department of Laboratory Medicine, Lund University, Medicon Village building 404A3, 22381 Lund, Sweden. 'Sahlgrenska Cancer Center, University of Gothenburg, 40530 Gothenburg, Sweden. ${ }^{8}$ Breakthrough Breast Cancer Unit, School of Cancer and Imaging Sciences, Paterson Institute for Cancer Research, University of Manchester, Wilmslow Road, Manchester M20 4BX, UK.

Received: 3 October 2013 Accepted: 11 February 2014 Published: 22 February 2014

\section{References}

1. Sudol M: Yes-associated protein (YAP65) is a proline-rich phosphoprotein that binds to the $\mathrm{SH} 3$ domain of the Yes proto-oncogene product. Oncogene 1994, 9:2145-2152

2. Hong W, Guan KL: The YAP and TAZ transcription co-activators: key downstream effectors of the mammalian Hippo pathway. Semin Cell Dev Biol 2012, 23:785-793.

3. Gaffney CJ, Oka T, Mazack V, Hilman D, Gat U, Muramatsu T, Inazawa J, Golden A, Carey DJ, Faroog A, Tromp G, Sudol M: Identification, basic characterization and evolutionary analysis of differentially spliced mRNA isoforms of human YAP1 gene. Gene 2012, 509:215-222.

4. Ota M, Sasaki H: Mammalian Tead proteins regulate cell proliferation and contact inhibition as transcriptional mediators of Hippo signaling. Development 2008, 135:4059-4069.

5. Wu S, Liu Y, Zheng Y, Dong J, Pan D: The TEAD/TEF family protein Scalloped mediates transcriptional output of the Hippo growthregulatory pathway. Dev Cell 2008, 14:388-398.

6. Zhang L, Ren F, Zhang Q, Chen Y, Wang B, Jiang J: The TEAD/TEF family of transcription factor Scalloped mediates Hippo signaling in organ size control. Dev Cell 2008, 14:377-387.

7. Zhao B, Ye X, Yu J, Li L, Li W, Li S, Yu J, Lin JD, Wang CY, Chinnaiyan AM, Lai ZC, Guan KL: TEAD mediates YAP-dependent gene induction and growth control. Genes Dev 2008, 22:1962-1971.

8. Chen L, Chan SW, Zhang X, Walsh M, Lim CJ, Hong W, Song H: Structural basis of YAP recognition by TEAD4 in the hippo pathway. Genes Dev 2010, 24:290-300.

9. Zhao B, Kim J, Ye X, Lai ZC, Guan KL: Both TEAD-binding and WW domains are required for the growth stimulation and oncogenic transformation activity of yes-associated protein. Cancer Res 2009, 69:1089-1098,

10. Alarcon C, Zaromytidou Al, Xi Q, Gao S, Yu J, Fujisawa S, Barlas A, Miller AN, Manova-Todorova K, Macias MJ, Sapkota G, Pan D, Massague J: Nuclear CDKs drive Smad transcriptional activation and turnover in BMP and TGF-beta pathways. Cell 2009, 139:757-769.

11. Ferrigno O, Lallemand F, Verrecchia F, L'Hoste S, Camonis J, Atfi A, Mauviel A: Yes-associated protein (YAP65) interacts with Smad7 and potentiates its inhibitory activity against TGF-beta/Smad signaling. Oncogene 2002, 21:4879-4884.

12. Komuro A, Nagai $M$, Navin $N E$, Sudol M: WW domain-containing protein YAP associates with ErbB-4 and acts as a co-transcriptional activator for the carboxyl-terminal fragment of ErbB-4 that translocates to the nucleus. J Biol Chem 2003, 278:33334-33341.

13. Strano S, Munarriz E, Rossi M, Castagnoli L, Shaul Y, Sacchi A, Oren M, Sudol M, Cesareni G, Blandino G: Physical interaction with Yes-associated protein enhances p73 transcriptional activity. J Biol Chem 2001, 276:15164-15173.

14. Vassilev A, Kaneko K, Shu H, Zhao Y, DePamphilis ML: TEAD/TEF transcription factors utilize the activation domain of YAP65, a Src/Yes-associated protein localized in the cytoplasm. Genes Dev 2001, 15:1229-1241.

15. Zaidi SK, Sullivan AJ, Medina R, Ito Y, van Wijnen AJ, Stein JL, Lian JB, Stein GS: Tyrosine phosphorylation controls Runx2-mediated subnuclear targeting of YAP to repress transcription. Embo J 2004, 23:790-799.

16. Overholtzer M, Zhang J, Smolen GA, Muir B, Li W, Sgroi DC, Deng CX, Brugge JS, Haber DA: Transforming properties of YAP, a candidate oncogene on the chromosome 11q22 amplicon. Proc Natl Acad Sci U S A 2006, 103:12405-12410.

17. Lamar JM, Stern P, Liu H, Schindler JW, Jiang ZG, Hynes RO: The Hippo pathway target, YAP, promotes metastasis through its TEAD-interaction domain. Proc Natl Acad Sci U S A 2012, 109:E2441-2450.

18. Wang X, Su L, Ou Q: Yes-associated protein promotes tumour development in luminal epithelial derived breast cancer. Eur J Cancer 2012, 48:1227-1234

19. Zhi X, Zhao D, Zhou Z, Liu R, Chen C: YAP promotes breast cell proliferation and survival partially through stabilizing the KLF5 transcription factor. Am J Pathol 2012, 180:2452-2461.

20. Santarius T, Shipley J, Brewer D, Stratton MR, Cooper CS: A census of amplified and overexpressed human cancer genes. Nat Rev Cancer 2010 10:59-64.

21. Zender L, Spector MS, Xue W, Flemming P, Cordon-Cardo C, Silke J, Fan ST, Luk JM, Wigler M, Hannon GJ, Mu D, Lucito R, Powers S, Lowe SW: Identification and validation of oncogenes in liver cancer using an integrative oncogenomic approach. Cell 2006, 125:1253-1267.

22. Muramatsu T, Imoto I, Matsui T, Kozaki K, Haruki S, Sudol M, Shimada Y, Tsuda H, Kawano T, Inazawa J: YAP is a candidate oncogene for esophageal squamous cell carcinoma. Carcinogenesis 2011, 32:389-398.

23. Wang Y, Dong Q, Zhang Q, Li Z, Wang E, Qiu X: Overexpression of yes-associated protein contributes to progression and poor prognosis of non-small-cell lung cancer. Cancer Sci 2010, 101:1279-1285.

24. Zhang X, George J, Deb S, Degoutin JL, Takano EA, Fox SB, Bowtell DD, Harvey KF: The Hippo pathway transcriptional co-activator, YAP, is an ovarian cancer oncogene. Oncogene 2011, 30:2810-2822.

25. Yuan M, Tomlinson V, Lara R, Holliday D, Chelala C, Harada T, Gangeswaran R, Manson-Bishop C, Smith P, Danovi SA, Pardo O, Crook T, Mein CA, Lemoine NR, Jones LJ, Basu S: Yes-associated protein (YAP) functions as a tumor suppressor in breast. Cell Death Differ 2008, 15:1752-1759.

26. Carter SL, Negrini M, Baffa R, Gillum DR, Rosenberg AL, Schwartz GF, Croce CM: Loss of heterozygosity at 11q22-q23 in breast cancer. Cancer Res 1994, 54:6270-6274.

27. Gudmundsson J, Barkardottir RB, Eiriksdottir G, Baldursson T, Arason A, Egilsson V, Ingvarsson S: Loss of heterozygosity at chromosome 11 in breast cancer: association of prognostic factors with genetic alterations. Br J Cancer 1995, 72:696-701.

28. Hampton GM, Mannermaa A, Winqvist R, Alavaikko M, Blanco G, Taskinen PJ, Kiviniemi H, Newsham I, Cavenee WK, Evans GA: Loss of heterozygosity in sporadic human breast carcinoma: a common region between 11q22 and 11q23.3. Cancer Res 1994, 54:4586-4589.

29. Koreth J, Bakkenist CJ, McGee JO: Allelic deletions at chromosome 11q22-q23.1 and 11q25-qterm are frequent in sporadic breast but not colorectal cancers. Oncogene 1997, 14:431-437.

30. Tomlinson IP, Nicolai H, Solomon E, Bodmer WF: The frequency and mechanism of loss of heterozygosity on chromosome 11q in breast cancer. J Pathol 1996, 180:38-43.

31. Matallanas D, Romano D, Yee K, Meissl K, Kucerova L, Piazzolla D, Baccarini M, Vass JK, Kolch W, O'Neill E: RASSF1A elicits apoptosis through an MST2 pathway directing proapoptotic transcription by the p73 tumor suppressor protein. Mol Cell 2007, 27:962-975.

32. Steinhardt AA, Gayyed MF, Klein AP, Dong J, Maitra A, Pan D, Montgomery EA, Anders RA: Expression of Yes-associated protein in common solid tumors. Hum Pathol 2008, 39:1582-1589.

33. Tufail R, Jorda M, Zhao W, Reis I, Nawaz Z: Loss of Yes-associated protein (YAP) expression is associated with estrogen and progesterone receptors negativity in invasive breast carcinomas. Breast Cancer Res Treat 2012, 131:743-750.

34. Helczynska K, Larsson AM, Holmquist Mengelbier L, Bridges E, Fredlund E, Borgquist S, Landberg G, Pahlman S, Jirstrom K: Hypoxia-inducible factor2alpha correlates to distant recurrence and poor outcome in invasive breast cancer. Cancer Res 2008, 68:9212-9220.

35. Rexhepaj E, Brennan DJ, Holloway P, Kay EW, McCann AH, Landberg G, Duffy MJ, Jirstrom K, Gallagher WM: Novel image analysis approach for quantifying expression of nuclear proteins assessed by immunohistochemistry: application to measurement of oestrogen and progesterone receptor levels in breast cancer. Breast Cancer Res 2008, 10:R89.

36. Ryden L, Jonsson PE, Chebil G, Dufmats M, Ferno M, Jirstrom K, Kallstrom AC, Landberg G, Stal O, Thorstenson S, Nordenskjold B: Two years of adjuvant 
tamoxifen in premenopausal patients with breast cancer: a randomised, controlled trial with long-term follow-up. Eur J Cancer 2005, 41:256-264.

37. Sims AH, Smethurst GJ, Hey Y, Okoniewski MJ, Pepper SD, Howell A, Miller CJ, Clarke RB: The removal of multiplicative, systematic bias allows integration of breast cancer gene expression datasets - improving meta-analysis and prediction of prognosis. BMC Med Genomics 2008, 1:42.

38. Chin K, DeVries S, Fridlyand J, Spellman PT, Roydasgupta R, Kuo WL, Lapuk A, Neve RM, Qian Z, Ryder T, Chen F, Feiler H, Tokuyasu T, Kingsley C, Dairkee S, Meng Z, Chew K, Pinkel D, Jain A, Ljung BM, Esserman L, Albertson DG, Waldman FM, Gray JW: Genomic and transcriptional aberrations linked to breast cancer pathophysiologies. Cancer Cell 2006, 10:529-541.

39. Desmedt C, Piette F, Loi S, Wang Y, Lallemand F, Haibe-Kains B, Viale G, Delorenzi M, Zhang Y, D'Assignies MS, Bergh J, Lidereau R, Ellis P, Harris AL, Klijn JG, Foekens JA, Cardoso F, Piccart MJ, Buyse M, Sotiriou C: Strong time dependence of the 76-gene prognostic signature for node-negative breast cancer patients in the TRANSBIG multicenter independent validation series. Clin Cancer Res 2007, 13:3207-3214.

40. Ivshina AV, George J, Senko O, Mow B, Putti TC, Smeds J, Lindahl T, Pawitan Y, Hall P, Nordgren H, Wong JE, Liu ET, Bergh J, Kuznetsov VA, Miller LD: Genetic reclassification of histologic grade delineates new clinical subtypes of breast cancer. Cancer Res 2006, 66:10292-10301.

41. Pawitan $Y$, Bjohle J, Amler L, Borg AL, Egyhazi S, Hall P, Han X, Holmberg L, Huang F, Klaar S, Liu ET, Miller L, Nordgren H, Ploner A, Sandelin K, Shaw PM, Smeds J, Skoog L, Wedren S, Bergh J: Gene expression profiling spares early breast cancer patients from adjuvant therapy: derived and validated in two population-based cohorts. Breast Cancer Res 2005, 7:R953-964.

42. Sotiriou C, Wirapati $P$, Loi $S$, Harris A, Fox S, Smeds J, Nordgren H, Farmer $P$, Praz V, Haibe-Kains B, Desmedt C, Larsimont D, Cardoso F, Peterse H, Nuyten D, Buyse M, Van de Vijver MJ, Bergh J, Piccart M, Delorenzi M: Gene expression profiling in breast cancer: understanding the molecular basis of histologic grade to improve prognosis. J Natl Cancer Inst 2006, 98:262-272.

43. Wang Y, Klijn JG, Zhang Y, Sieuwerts AM, Look MP, Yang F, Talantov D, Timmermans M, Meijer-van Gelder ME, Yu J, Jatkoe T, Berns EM, Atkins D, Foekens JA: Gene-expression profiles to predict distant metastasis of lymph-node-negative primary breast cancer. Lancet 2005, 365:671-679.

44. Chin SF, Teschendorff AE, Marioni JC, Wang Y, Barbosa-Morais NL, Thorne NP, Costa JL, Pinder SE, van de Wiel MA, Green AR, Ellis IO, Porter PL, Tavare S, Brenton JD, Ylstra B, Caldas C: High-resolution aCGH and expression profiling identifies a novel genomic subtype of ER negative breast cancer. Genome Biol 2007, 8:R215.

45. Jirstrom K, Ryden L, Anagnostaki L, Nordenskjold B, Stal O, Thorstenson S, Chebil G, Jonsson PE, Ferno M, Landberg G: Pathology parameters and adjuvant tamoxifen response in a randomised premenopausal breast cancer trial. J Clin Pathol 2005, 58:1135-1142.

46. Jirstrom K, Stendahl M, Ryden L, Kronblad A, Bendahl PO, Stal O, Landberg G: Adverse effect of adjuvant tamoxifen in premenopausal breast cancer with cyclin D1 gene amplification. Cancer Res 2005, 65:8009-8016.

47. Lundgren K, Brown M, Pineda S, Cuzick J, Salter J, Zabaglo L, Howell A Dowsett M, Landberg G: Effects of cyclin D1 gene amplification and protein expression on time to recurrence in postmenopausal breast cancer patients treated with anastrozole or tamoxifen: a TransATAC study. Breast Cancer Res 2012, 14:R57.

48. Ormandy CJ, Musgrove EA, Hui R, Daly RJ, Sutherland RL: Cyclin D1, EMS1 and 11 q13 amplification in breast cancer. Breast Cancer Res Treat 2003, 78:323-335.

49. Schuuring $E$, Verhoeven $E$, van Tinteren $H$, Peterse JL, Nunnink $B$, Thunnissen FB, Devilee P, Cornelisse CJ, van de Vijver MJ, Mooi WJ: Amplification of genes within the chromosome $11 \mathrm{q} 13$ region is indicative of poor prognosis in patients with operable breast cancer. Cancer Res 1992, 52:5229-5234.

50. Moleirinho S, Chang N, Sims AH, Tilston-Lunel AM, Angus L, Steele A Boswell V, Barnett SC, Ormandy C, Faratian D, Gunn-Moore FJ, Reynolds PA: KIBRA exhibits MST-independent functional regulation of the Hippo signaling pathway in mammals. Oncogene 2013, 32:1821-1830

51. Bardou VJ, Arpino G, Elledge RM, Osborne CK, Clark GM: Progesterone receptor status significantly improves outcome prediction over estrogen receptor status alone for adjuvant endocrine therapy in two large breast cancer databases. J Clin Oncol 2003, 21:1973-1979.

52. Wijayaratne $A L, M c D o n n e l l ~ D P$ : The human estrogen receptor-alpha is a ubiquitinated protein whose stability is affected differentially by agonists, antagonists, and selective estrogen receptor modulators. J Biol Chem 2001, 276:35684-35692.

53. Moynahan ME: The cancer connection: BRCA1 and BRCA2 tumor suppression in mice and humans. Oncogene 2002, 21:8994-9007.

54. Subik K, Lee JF, Baxter L, Strzepek T, Costello D, Crowley P, Xing L, Hung MC, Bonfiglio T, Hicks DG, Tang P: The expression patterns of ER, PR, HER2, CK5/ 6, EGFR, Ki-67 and AR by immunohistochemical analysis in breast cancer cell lines. Breast Cancer: Basic Clin Res 2010, 4:35-41.

55. Bayliss J, Hilger A, Vishnu P, Diehl K, El-Ashry D: Reversal of the estrogen receptor negative phenotype in breast cancer and restoration of antiestrogen response. Clin Cancer Res 2007, 13:7029-7036.

56. Chen D, Sun Y, Wei Y, Zhang P, Rezaeian AH, Teruya-Feldstein J, Gupta S,

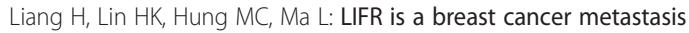
suppressor upstream of the Hippo-YAP pathway and a prognostic marker. Nat Med 2012, 18:1511-1517.

57. Reis-Filho JS, Pusztai L: Gene expression profiling in breast cancer: classification, prognostication, and prediction. Lancet 2011, 378:1812-1823.

58. Lundgren K, Holm K, Nordenskjold B, Borg A, Landberg G: Gene products of chromosome 11q and their association with CCND1 gene amplification and tamoxifen resistance in premenopausal breast cancer. Breast Cancer Res 2008, 10:R81.

59. Holm K, Staaf J, Jonsson G, Vallon-Christersson J, Gunnarsson H, Arason A, Magnusson L, Barkardottir RB, Hegardt C, Ringner M, Borg A: Characterisation of amplification patterns and target genes at chromosome 11q13 in CCND1-amplified sporadic and familial breast tumours. Breast Cancer Res Treat 2012, 133:583-594.

60. Dhananjayan SC, Ramamoorthy S, Khan OY, Ismail A, Sun J, Slingerland J, O'Malley BW, Nawaz Z: WW domain binding protein-2, an E6-associated protein interacting protein, acts as a coactivator of estrogen and progesterone receptors. Mol Endocrinol 2006, 20:2343-2354.

61. Lee YJ, Gorski J: Estrogen-induced transcription of the progesterone receptor gene does not parallel estrogen receptor occupancy. Proc Natl Acad Sci U S A 1996, 93:15180-15184.

62. Poole AJ, Li Y, Kim Y, Lin SC, Lee WH, Lee EY: Prevention of Brca1-mediated mammary tumorigenesis in mice by a progesterone antagonist. Science 2006, 314:1467-1470

63. Wang S, Li Y, Hsu PH, Lee SY, Kim Y, Lee EY: Progesterone receptor A stability is mediated by GSK-3beta kinase in the Brca1-deficient mammary gland. J Biol Chem 2013, 288:26265-26274.

64. Sabbah M, Courilleau D, Mester J, Redeuilh G: Estrogen induction of the cyclin D1 promoter: involvement of a cAMP response-like element. Proc Natl Acad Sci U S A 1999, 96:11217-11222.

doi:10.1186/1471-2407-14-119

Cite this article as: Lehn et al:: Decreased expression of Yes-associated protein is associated with outcome in the luminal A breast cancer subgroup and with an impaired tamoxifen response. BMC Cancer 2014 14:119.

\section{Submit your next manuscript to BioMed Central and take full advantage of:}

- Convenient online submission

- Thorough peer review

- No space constraints or color figure charges

- Immediate publication on acceptance

- Inclusion in PubMed, CAS, Scopus and Google Scholar

- Research which is freely available for redistribution 